\title{
Current State of the Art in Preclinical Research in Alzheimer's Disease - A Focus on Mode of Action in Pharmacological and Non-pharmacological Approaches
}

\author{
Kiren Ubhi ${ }^{1}$ and Eliezer Masliah ${ }^{2}$
}

1. Postgraduate Research Fellow, Department of Neurosciences; 2. Professor of Neuroscience and Pathology,
Departments of Neurosciences and Pathology, University of California, San Diego, La Jolla, California, US

\begin{abstract}
Alzheimer's disease (AD) is an age-related neurodegenerative disorder characterised by progressive memory deficits and other cognitive disturbances. Neuropathologically, AD is characterised by synaptic deficits, progressive loss of neocortical, limbic and basal forebrain cholinergic neurons and the abnormal extracellular accumulation of amyloid-beta $(A B)$ and the intracellular aggregation of the cytoskeletal protein tau. Currently available AD therapies either only temporarily delay disease progression or address the symptoms but are unable to alter the underlying mechanisms of disease. Therefore, ongoing $A D$ research is focused at better understanding pathogenesis and at developing disease-modifying experimental therapeutic approaches. This review will summarise the main areas of preclinical research for AD therapeutics that includes those aimed at modulating the processing of amyloid precursor protein (APP) and the production of $A \beta$; ameliorating the pathological accumulation of $A \beta$ or tau; augmenting neuroprotective activities in the AD brain; and augmenting neurorestoration in the $A D$ brain. The review will also discuss a novel multimodal therapeutic approach to $A D$ using Cerebrolysin, a peptidergic mixture with neurotrophic-like effects.
\end{abstract}

\section{Keywords}

Neurotrophic factors, synapses, ageing, neurodegeneration, Cerebrolysin

Disclosure: The authors are consultants to EVER Neuro Pharma.

Received: 19 September 2012 Accepted: 5 November 2012 Citation: European Neurological Review, 2012;7(4):216-23 DOI:10.17925/ENR.2012.07.04.216 Correspondence: Eliezer Masliah, Departments of Neurosciences and Pathology, University of California, San Diego, 9500 Gilman Drive, La Jolla, CA 92093-0624, US. E: emasliah@ucsd.edu

Support: The publication of this article was funded by EVER Neuro Pharma GmbH. The views and opinions expressed are those of the authors and not necessarily those of EVER Neuro Pharma GmbH.

Alzheimer's disease (AD) is the seventh most prevalent cause of death in the US and is the leading cause of dementia, affecting more than 5 million Americans and 26 million people worldwide. Without an effective therapy it is estimated that the number of patients with $A D$ will double by the year 2050. ' Cognitive impairment in patients with $A D$ is closely associated with loss of synapses and the formation of neurofibrillary tangles (NFT) in the neocortex and limbic system..$^{2-6}$ The two major neuropathological findings in patients with $A D$ are extracellular plaques formed mainly of the amyloid-beta $(A \beta)$ peptide, ${ }^{7-9}$ and intracellular NFT, containing hyperphosphorylated tau. ${ }^{10-12}$ Several lines of investigation support the view that increasing levels of $A \beta_{1-42}$, the proteolytic product of amyloid precursor protein (APP) metabolism, might be centrally involved in the pathogenesis of $A D^{7-9,13}$ and it has been proposed that in $A D$, progressive accumulation of $A \beta$ might be involved in the mechanisms underlying NFT formation and synaptic loss. ${ }^{14-17}$ More specifically in recent years the potential role of neurotoxic $A \beta$ oligomers has emerged as a topic of considerable interest. ${ }^{18-21}$

AD medications currently prescribed are aimed at individuals with mild to moderate $A D$ and include drugs such as donepezil, rivastigmine and galantamine, all of which are acetylcholinesterase inhibitors and work by preventing the breakdown of acetylcholine and stimulating nicotinic receptors to release acetylcholine in the brain. Memantine, another drug currently approved for use in moderate to severe $A D$, is an $\mathrm{N}$-methyl-D-aspartate (NMDA) receptor antagonist and acts on the glutamatergic system by blocking the toxic effects associated with excess glutamate, thereby regulating glutamate activation. In addition to its activity at the NMDA receptor, memantine also acts as a non-competitive antagonist at the 5-hydroxytryptamine (5-HT) serotonin and nicotinic receptors. Although each of these drugs has demonstrated treatment effects on the cognitive, functional and behavioural problems commonly associated with $A D$, these drugs simply slow the progression of $A D$ but do nothing to tackle the underlying pathogenesis. In this context, there has been real interest in elucidating the main pathways involved in $A D$ pathogenesis and developing therapies acting on these key pathways.

This review will focus on preclinical experimental therapies being investigated for $A D$, with particular focus on the role of multimodal therapies, typified by Cerebrolysin (CBL), a peptide mixture with neurotrophic-like effects. 


\section{Areas of Preclinical Therapeutical Research}

The last few decades have seen an exponential increase in our understanding of mechanisms underlying AD pathogenesis, and this has led to increased diversity in the modes of action of experimental AD therapies (see Figure 1).

Many of the current experimental approaches towards AD therapy fall into the following broad categories:

- those aimed at modulating the processing of APP and the production of $A \beta$;

- those aimed at ameliorating the pathological accumulation of $A \beta$ or tau;

- those aimed at augmenting neuroprotective activities in the $A D$ brain; and

- those aimed at augmenting neurorestoration in the AD brain.

Each of these major approaches will be addressed below; additionally we shall highlight $\mathrm{CBL}$, a unique neurotrophic therapeutical approach for AD that has a multimodal mechanism of action. However, it should be noted that some key approaches to AD therapy, such as modulation of the inflammatory response, are topics in their own right and are too broad for the scope of this review; for a discussion on this topic the reader is referred to a number of recent review articles. ${ }^{22,23}$

\section{Therapies Aimed at Modulating Amyloid Precursor Protein Processing}

$A \beta$ is formed by the proteolytic cleavage of the APP, a single-pass transmembrane protein with a large extracellular domain. APP processing occurs as a result of the sequential action of a group of enzymes called secretases. Secretase processing can occur via two separate pathways, the first of these is the non-amyloidogenic pathway, in which the sequential action of $\alpha$ - and then $\gamma$-secretase results in the formation a C-terminal fragment, a soluble-APP $\alpha$ and eventually the APP intracellular domain (AICD). ${ }^{24,25}$ The second pathway is the amyloidogenic pathway and involves the initial cleavage of APP by $\beta$-secretase followed by the action of $\gamma$-secretase which now generates multiple forms of $A \beta$ with $A \beta_{1-40}$ and $A \beta_{1-42}$

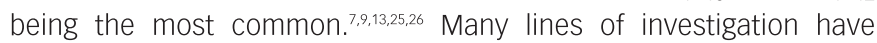
shown that $A \beta$ generated via the amyloidogenic pathway has a strong propensity to form fibrils and to aggregate, with $A \beta_{1-42}$ being more aggregenic than $A \beta_{1-40} \cdot{ }^{13,27}$ The processing of $A P P$ to $A \beta$ and the subsequent aggregation of $A \beta$ are thought to be key pathological events in the AD cascade and a great deal of research has focused on factors involved in APP processing and methods to modulate processing along the amyloidogenic pathway. ${ }^{7,9,26}$

Most therapeutic approaches for AD have been focused at reducing $A \beta$ accumulation by decreasing APP metabolism by blocking $\beta$ - or $\gamma$-secretase activity, ${ }^{28-33}$ by preventing aggregation of $A \beta^{34,35}$ or by promoting clearance. ${ }^{36,37}$

Secretase inhibitors have been designed against both $\beta$ - or $\gamma$-secretases and both have been shown to lower plasma A $\beta$ in rodents, ${ }^{38}$ and in cerebrospinal fluid (CSF) and plasma in primate models of the disease. ${ }^{39}$ However, the development of these inhibitors has been hampered by the need to have them pass through the blood-brain barrier (BBB), by off-target effects (such as those associated with $\gamma$-secretase inhibitors) and their ability to cleave Notch (a transmembrane receptor involved in regulating cell fate
Figure 1: Points of Entry for Experimental Treatments for Alzheimer Disease

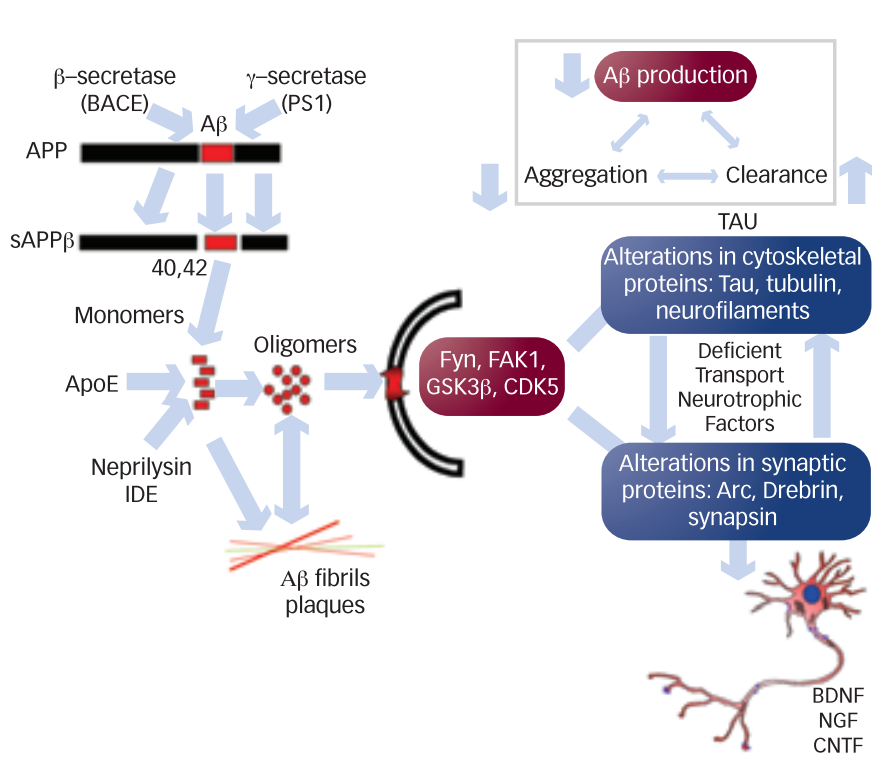

$A \beta=$ amyloid-beta; $A P O E=$ apolipoprotein $E ; A P P=$ amyloid precursor protein;

$B D N F=$ brain-derived neurotrophic factor; $C D K 5=$ cyclin-dependent kinase $5 ;$ CNTF = ciliary neurotrophic factor; FAK1 = focal adhesion kinase 1; GSK3 $\beta=$ glycogen synthase kinase 3 beta; IDE = insulin-degrading enzyme; $P S 1$ = presenilin 1; NGF = nerve growth factor; $S A P P \beta=$ soluble APP beta.

decisions) and finally with adverse side effects and toxicity. ${ }^{40,41}$ Two large Phase III clinical trials of semagacestat, a $\gamma$-secretase inhibitor, in mild to moderate $A D$ patients were prematurely terminated due to cognitive and functional side effects of the drug. ${ }^{42}$ The recent results from clinical trials with secretase inhibitors seem to suggest that despite showing early promise at the preclinical stage, they have failed to live up to expectations in clinical trials. At present, most in vivo experimental research has been focused at testing $\gamma$-secretase modulators and at developing more specific and BBB penetrating $\beta$-secretase inhibitors. Work is also underway to develop compounds that stimulate $\alpha$-secretases. ${ }^{43}$

\section{Therapies Aimed at Ameliorating the Pathological Accumulation of Amyloid-beta or Tau}

This includes therapies aimed at reducing the aggregation of $A \beta$ and $\operatorname{tau}^{44-47}$ and at increasing clearance. Strategies contemplated for the removal of pathologically accumulated proteins include approaches such as chaperone-mediated clearing, stimulation of autophagy or proteosomal activity or increasing the proteolytic cleavage (for example by using Neprilysin to cleave $A \beta$ ) or by modulating chaperone-like activity. ${ }^{48,49}$

Chaperone-mediated clearance co-opts the natural ability of all cells to conduct a quality control process designed to prevent the build-up of abnormally folded or toxically aggregated proteins. Chaperones can inhibit protein misfolding, interfere with abnormal aggregation and may even promote the correct folding of misfolded proteins..$^{50,51}$ chaperones can also target misfolded proteins for degradation via various cellular pathways including the ubiquitin-proteosome pathway or chaperone-mediated autophagy. ${ }^{52-54}$ The best characterised chaperones are the heat shock proteins (HSPS) ${ }^{55-57}$ and a number of studies suggest that up regulation of HSPS can suppress A $\beta$ aggregation and toxicity. ${ }^{58,59}$ Collectively, these studies support a potential therapeutic application of chaperone function modulation for disorders 
that are characterised by protein misfolding and aggregation, such as AD. Moreover, HSPS such as Hsp70 and Hsp90 have been shown to play a significant role in tau clearance and processing. ${ }^{60,61}$

An alternative approach to the clearance of proteins has been the use of antibodies targeting pathological forms of $A \beta$ or tau. The observation that elderly $A D$ patients express autoantibodies against $A \beta^{62}$ and tau ${ }^{63}$ suggests that the immune system is capable of mounting a response against the pathological forms of these proteins. In this context a number of groups conducted studies aimed at inducing or enhancing this immune response. To date, immunotherapeutic approaches to $A D$ have mostly targeted $A \beta$, as it is a secreted protein that can be found in plasma and CSF and is easily accessible to circulating antibodies. ${ }^{64}$

The first immunotherapeutic approach based on preclinical pioneering work by Shenck et al. ${ }^{65,66}$ to reach the clinical trial stage was an active immunisation protocol using the AN1792 antibody (Elan Pharmaceuticals, Inc). A number of positive features of this trial included the ease of administration and the prospect of lifelong immunity. However, this trial was halted in 2002 when a small number of participants reported adverse side effects, ${ }^{67}$ these effects have since been linked to the choice of adjuvant and a $T$ cell recognition site. Subsequent clinical trials have included active immunisation with CAD-106 (Novartis), a peptide vaccine that contains a short $\mathrm{N}$-terminal fragment of $A \beta$ which reportedly does not induce the T cell response observed with AN1792. ${ }^{64}$ Results from this trial report no significant differences between CSF A $\beta$ levels and magnetic resonance imaging (MRI) whole brain volumes between treated and placebo patients. ${ }^{68}$

Based on preclinical studies in the platelet-derived growth factor beta-APP (PDAPP) model of $A D_{1}^{69-71}$ a transgenic ( $\mathrm{tg}$ ) mouse model of $A D$ that overexpresses mutuant APP, a number of passive immunisation approaches have also reached clinical trial stage including the Phase II Elan/Wyeth antibody Bapineuzumab trial, which showed side effects such as vascular oedema in the high dose cohort (2.0 $\mathrm{mg} / \mathrm{kg}$ ) resulting in this dose being excluded from the Phase III trial. ${ }^{72-74}$ Bapineuzumab has also been reported to reduce cortical PiB retention in $A D$ patients. ${ }^{75}$ While recent Bapineuzumab clinical trial results have failed to produce significant cognitive improvements in patients, results from animal models suggest that this approach may be better suited to the early, preclinical stages of the disease and therefore may have a more preventative rather that therapeutic function. Another passive immunisation approach is the humanised monocolonal antibody Solanezumab from Eli Lilly, which was also well-tolerated at lower doses and showed a dose-dependent increase in CSF and plasma levels of $A \beta .^{76}$

In recent years some groups have investigated the possibility of utilising immunotherapy to target abnormally phosphorylated tau. As previously mentioned, NFT form the other neuropathological hallmark of AD, these are intracellular accumulations of tau, a microtubule associated protein, which is hyperphosphorylated at multiple epitopes. ${ }^{77-79}$ This hyperphosphorylation has been linked to tau propensity to aggregate and a loss-of-function with regard to the ability of tau to stabilise the microtubule structure and facilitate axonal transport. ${ }^{80-84}$

Two recent studies have shown that immunisation against phosphorylated forms of tau might be effective at reducing NFT pathology in vivo and slowing the progression of behavioural deficits in tg mouse models of $A D .85-87$

Unlike $A \beta$, which is a predominantly extracellular protein, tau and the hyperphosphorylated forms of tau are intracellular and have traditionally thought to be inaccessible to antibodies. However, recent work has shown that aggregates of $\alpha$-synuclein, an intracellular synaptic protein that accumulates in the brains of patients with Parkinson's disease (PD) and AD were reduced following active ${ }^{88}$ and passive $^{89}$ immunisation against $\alpha$-synuclein in a tg mouse model, indicating that intracellular proteins could also be potential targets of immunisation. This might be related to recent findings in in vivo models showing that aggregated $\alpha$-synuclein ${ }^{90}$ and tau ${ }^{91,92}$ can be released from neurons and propagate to other cells in a prion-like fashion.

In 2007, Asuni et al. demonstrated that active immunisation with the tau peptide 379-408, phosphorylated at serine residues 396 and 404 (Tau379-408: Ser396/404) was effective at reducing the levels of tau aggregates in the brain of P301L tg mice, a model of tauopathy..$^{85}$ These particular epitopes were chosen as they were known to be pathological forms of tau found in AD brains and had been reported to increase the fibrillogenic nature of tau increasing its propensity to assemble into paired helical filaments (PHFs). Asuni et al. showed that active immunisation with the Tau379-408: Ser396/404 peptide was capable of inducing antibodies against the phosphorylated forms of tau and in the immunised mice the reduction in tau aggregation was accompanied by an amelioration of the sensorimotor deficits associated with tau pathology. ${ }^{85,87}$

\section{Neuroprotective Approaches to Alzheimer's Disease Involving Key Pathways and Signalling Molecules}

Oxidative stress has been proposed to be a key pathway underlying pathogenesis in $A D .{ }^{93,94} A \beta$ has been reported to bind to mitochondrial membranes, interact with heme and interfere with the normal electron flow through the respiratory chain, resulting in a faulty mitochondrial energy metabolism and in an increased production of reactive oxygen species (ROS). ${ }^{95}$ Antioxidant therapies such as vitamin $\mathrm{E}$ and resveratrol have been investigated in animal models for their therapeutic potential in $A D$, with varying degrees of success. ${ }^{95}$ While memantine, a currently available AD therapy, targets the NMDA receptor, further studies on the glutamate system in $A D$ have focused on the role of other glutamate receptors including alpha-amino-3-hydroxy-5-methylisoxazole-4-propionate (AMPA) and metabotropic glutamate receptors. ${ }^{96}$

The loss of AMPA receptor-mediated transmission in $A D$ has been reported to be modulated by $A \beta_{1-42}{ }^{97-99} \mathrm{~A}$ recent study found that an agent that blocks AMPA receptor desensitisation, cyclothiazide, prevented oligomer-induced reduction of excitatory postsynaptic currents (EPSCS), consistent with $A \beta$ acting by inhibiting glutamate uptake..$^{100}$ Furthermore, micromolar concentrations of synthetic $A \beta_{1-42}$ oligomers, especially in the presence of cyclothiazide, can rapidly trigger AMPA receptor-dependent inward currents and delayed neurodegeneration in cultured cortical neurons. ${ }^{101}$ Taken together, these findings indicate that agents designed to directly boost AMPA receptor function in AD may have a relatively narrow therapeutic window.

Stimulation of Group 1 metabotropic glutamate receptors (mGluR 1 and 5) leads to activation of a wide variety of signalling pathways and other 
downstream protein kinases, such as extracellular signal-regulated protein kinases (ERK) 1/2 and Akt, which in turn have been implicated in cellular growth, differentiation and survival. ${ }^{102}$ mGluR1/5 signal transduction is complex and involves multiple partners, and alterations in mGluR signalling have been implicated in neurodegenerative disorders such as $A D, P^{103}$ and Huntington's disease. ${ }^{104}$ mGluR5 inhibitors, currently employed for the treatment of Fragile $X$ syndrome, have been shown to reduce $A \beta$ production in rodent models. ${ }^{102}$

A number of groups have investigated signalling pathways involved in $A D$, and the Wnt pathway has been a particular area of interest. Tight regulation of Wht signalling is a prerequisite for normal neural development as well as for the maintenance of neuronal homeostasis and synaptic plasticity in adults. ${ }^{105,106}$ Previous studies have linked Wnt signalling to neurodegenerative disorders such as $A D .{ }^{107,108}$ In fact, strong evidence suggests that a loss of Wnt function is implicated in the pathophysiology of neuronal degeneration of AD. Compounds such rosiglitazone, a peroxisome proliferator-activated receptor- $\gamma$ agonist, and lithium have been shown to attenuate the neurotoxic effects of $A \beta$, both of these drugs activate Wht signalling. ${ }^{109}$ In addition to its effect on glycogen synthase kinase 3 beta (GSK3 $\beta$ ), lithium is known to modulate cyclin-dependent kinase 5 (CDK5), another kinase that has been linked to the abnormal hyperphosphorylation of tau in AD. ${ }^{110,111}$

Oxidative stress, glutamate signalling and the Wnt signalling pathway are only a few of the pathways thought to play a role in AD. ${ }^{12}$ Given the number of alternate pathways implicated in AD, such as p38, Akt, C-Jun N-terminal kinase (Jnk), among others, it seems likely that the most efficacious $A D$ therapies would act upon a number of these pathways in tandem.

\section{Neurorestorative Approaches Aimed at Neurogenesis and Synaptic Plasticity}

Since the first report of the production of new neurons in the adult hippocampus, ${ }^{113}$ research has shown that various neurotransmitter systems, growth factors, neurotrophins, cytokines and hormones are major regulators of neurogenesis. ${ }^{114}$ Studies in tg animal models of different neurological disorders have shown significant alterations in neurogenesis in the hippocampus under pathological conditions. ${ }^{115}$

Interestingly, a number of molecules central to AD have been found to play a regulatory role in adult neurogenesis. ${ }^{116-118}$ Mutations of presenilin 1 (PS1) have been shown to negatively affect the production of new neurons. ${ }^{116,119,120}$ similarly, the proliferation and survival of neuronal precursor cells was shown to be reduced in tg mice expressing a chimeric mouse-human APP-695swe (APPSwe) polypeptide, a mutated form of APP that causes early onset familial AD (FAD). ${ }^{121}$

In the mature brain, neurogenesis is believed to play an important role in maintaining synaptic plasticity and memory formation in the hippocampus. ${ }^{87}$ In $A D$, the most significant correlate to the severity of cognitive impairment is the synaptic loss in the frontal cortex and the limbic system. ${ }^{122-125}$ Synaptotoxic effects have been observed with soluble $A \beta$ oligomers prepared from multiple sources such as synthetic A $\beta$ peptides, APP-transfected cell culture supernatants, APP tg mouse brain and even human $A D$ brain tissue. ${ }^{126}$ At nanomolar to low micromolar concentrations, soluble A $\beta$ oligomers impair excitatory synaptic transmission, inhibit long-term potentiation (LTP), induce loss of dendritic spines and impair rodent spatial memory. ${ }^{127-133}$ In contrast to suppression of LTP, long-term depression (LTD) is unaffected or even enhanced by $A \beta .^{134}$ Thus, in terms of synaptic plasticity, exposure to $A \beta$ seems to favour the weakening and oppose the strengthening of synapses. Consistent with its functional effects on LTP and LTD, prolonged exposure to $A \beta$ leads to morphological loss of synapses. ${ }^{126,135,136} A \beta_{1-42}$, which is more prone to aggregation and more toxic than $A \beta_{1-40}$, is also more effective at impairing LTP and reducing spine density. Furthermore, dysregulated cholinergic signalling is an early hallmark of $A D$ and it is interesting to note that $A \beta$ oligomers have been shown to induce cholinergic neurodegeneration in the nucleus basalis ${ }^{137}$ and, at nanomolar concentrations, to inhibit the activity of choline acetyltransferase (ChAT). ${ }^{138}$

Given the deficits in neurogenesis, synaptic plasticity and deficits in glutamatergic and cholinergic systems in $A D$, it would be reasonable to hypothesise that compounds capable of intervening in these processes would show a serious promise in the development of new treatments. One such type of compound may be related to modulation the activity of neurotrophic factors (NTFS). NTFs are secreted proteins that promote the differentiation, growth and maintenance of developing neurons and the survival of adult neurons ${ }^{139-141}$ and include members such as nerve growth factor (NGF) and brain-derived neurotrophic factor (BDNF), signalling molecules in various cellular pathways, which regulate development, proper functioning, survival and regeneration of nervous tissue under physiological conditions and most importantly after injury. NTFs including NGF and BDNF have been widely reported to be altered in a number of neurodegenerative disorders including $A D,{ }^{142-144}$ and many studies have looked at NTF replacement strategies in an effort to stave off neuronal dysfunction and death in these disorders with a number reporting beneficial effects. ${ }^{145}$ The results of the first clinical trial of NGF gene therapy in AD were published in $2005^{146}$ and reported no long-term adverse effects of implanting autologous fibroblasts genetically modified to express human NGF into the forebrain.

BDNF gene delivery into tg mice expressing mutated (Swedish K670M/N671L, London V7171) human (h) APP751 under control of the mouse thymus cell antigen-1 (mThy-1) promoter (mThy1-hAPP751 tg mice; Line 41$)^{147}$ reverses synapse loss, partially normalises aberrant gene expression, improves cell signalling and restores learning and memory. ${ }^{148}$ These outcomes occur independently of effects on amyloid plaque load. In aged rats, BDNF infusion reverses cognitive decline, improves age-related perturbations in gene expression and restores cell signalling. ${ }^{148}$ The therapeutic effects of BDNF have also been assessed in non-human primate models, where BDNF gene delivery to the entorhinal cortex, significantly ameliorated lesion-induced entorhinal cortical neuronal death, improved hippocampus-dependent memory and increased neuronal size. ${ }^{148}$

Given the large molecular weight of NTFs, such as NGF and BDNF in comparison with chemical compounds, the key challenge in the field of growth factor therapy is drug delivery to the CNS and to this end a number of NTF-based therapies are currently in the clinic, including those focusing on methods of delivering NTFs, particularly NGF (AAV-NGF, [CERE-110, NCT00876863]), encapsulated cell biodelivery of NGF [NCT01163825].

$A D$, like many neurodegenerative disorders, occurs as a result of the progressive loss of structural or functional integrity of neurons. In this context, many groups have tried to replace damages/lost neurons in the hope of restoring neuronal function and have explored stem cell therapy as an alternative neurorestorative approach in models of 


\section{Figure 2: Multimodal Mechanisms of Action of Cerebrolysin in Preclinical Models of Alzheimer Disease}

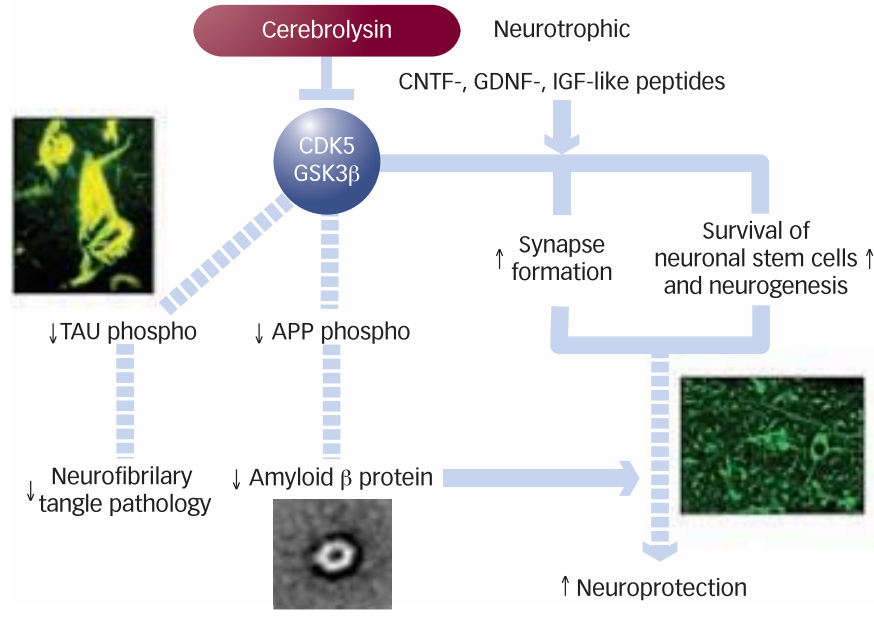

APP = amyloid precursor protein; $C D K 5=$ cyclin-dependent kinase $5 ;$ CNTF = ciliary neurotrophic factor; $G D N F=$ glial derived neurotrophic factor; $G S K 3 \beta=$ glycogen synthase kinase 3 beta; IGF = insulin-like growth factor.

neurodegenerative conditions such as PD. ${ }^{149}$ Rodent AD models receiving neural precursor cell (NPC) grafts demonstrate increased hippocampal synaptic density and increased cognitive function associated with BDNF production. . $^{150,151}$ Combining engineered growth factor overexpression with the benefits of NPC integration into neural networks may provide an enhanced approach to treating AD. The results of these will be interesting in light of recent stem cell studies in PD that have shown host to graft transmission of $\alpha$-synuclein. ${ }^{152,153}$

Given the multiple mechanisms associated with AD pathology, and the apparent failure of single-target approaches to therapeutics, it is likely that the most efficacious AD therapy will target multiple components of the AD pathophysiological cascade from the processing of APP, the abnormal accumulation of $A \beta$, hyperphosphorylation of tau combined with a neuroprotective and neurorestorative neurotrophic factor-like effect. ${ }^{154}$ It is most likely that truly disease-modifying treatment for $A D$ will be a multi-target compound with actions at intersecting nodes on pathogenic pathways associated with $A D$.

\section{A Multimodal Approach to Alzheimer's Disease - Preclinical Studies in Transgenic Mice}

One example of a multimodal approach to the treatment $A D$ is the $J 147$ compound, a curcumin derivative which has a broadly neuroprotective effect including the ability to prevent memory deficits in a tg mouse model of $A D$ associated with an increase in levels of BDNF and BDNF responsive proteins, enhancement of LTP, synaptic preservation, reduction oxidative stress and inflammation and lower levels of soluble $A \beta_{1-42}$ and $A \beta_{1-40} \cdot{ }^{155}$

Another interesting set of compounds that display a multimodal activity are antidepressants such as fluoxetine. This family of compounds increase levels of BDNF, glial derived neurotrophic factor (GDNF) and NGF, stimulate neurogenesis, are neuroprotective and stabilise mood. ${ }^{156-158} \mathrm{~A}$ further example of a model multimodal drug is $\mathrm{CBL}$, a neuropeptide preparation produced by a standardised enzymatic breakdown of purified brain proteins (see Figure 2). CBL contains low-molecular-weight peptides $(<10 \mathrm{kDa})$ and free amino acids and has been reported to have beneficial effects in $\mathrm{tg}$ models of
$\mathrm{AD}^{159-162}$ and in human clinical trials. ${ }^{163-165} \mathrm{CBL}$ is known to be composed of small peptides with neurotrophic activity similar to ciliary neurotrophic factor (CNTF), GDNF and insulin-like growth factors-1 and -2 (IGF-1, IGF-2) and it is the activity of these small peptides that are thought to be involved in the neuroprotective effects of CBL. ${ }^{166}$ In addition to effects on disease-related proteins, CBL has been reported to have neuroprotective actions, typified by studies that have shown that CBL protects cholinergic neurons after fimbria-fornix lesion ${ }^{167-169}$ as well as protecting the CNS in models of stroke. ${ }^{170} \mathrm{CBL}$ has recently been shown to modulate the pro-NGF/NGF balance in the mThy1-hAPP751 tg mice resulting in a concomitant amelioration of cholinergic deficits in these mice. ${ }^{171}$

In addition to its neurotrophic-like effects, CBL has been reported to reduce amyloid deposition; this has been linked to CBL-regulated modulation of APP maturation and its intracellular distribution. ${ }^{161}$ Studies in mThy1-hAPP751 tg mice have shown that CBL is able to modulate the activity of kinases involved in APP phosphorylation by reducing the levels of the active form of CDK5 and its activators p35 and p25 and increasing the level of inactive GSK-3 $\beta .^{161}$

Furthermore, since GSK-3 $\beta$ and CDK5 are known to phosphorylate tau at epitopes critical for the formation of NFTs, the effect of CBL treatment was investigated in mThy1-hAPP751 tg mice that received bilateral intrahippocampal adeno-associated virus (AAV2)-mutTAU injection and results from these studies confirmed the previously reported modulating effect of CBL on the activity of CDK5 and GSK-3 $\beta$ but also demonstrated a decreased abnormal phosphorylation of tau, resulting in improved neurodegenerative pathology in the hippocampus in the treated mice. ${ }^{172}$

Collectively these studies demonstrate that CBL is able to modulate the aggregenic properties of the key neuropathological hallmark proteins in $A D$, by either the modulation of APP maturation or modulation of tau hyperphosphorylation, in both cases CBL appears to be having this effect by virtue of its activity on key signalling molecules such as GSK3 $\beta$ and CDK5.

Neuropathological examination of mThy1-hAPP751 tg mice treated with $\mathrm{CBL}$ have shown that $\mathrm{CBL}$ promotes synaptic regeneration. After treatment with $\mathrm{CBL}$ for four weeks, brain sections immunolabelled with antibodies against synaptophysin, a synaptic marker protein showed preservation of synaptic terminals in the frontal cortex and hippocampus of treated mice, ${ }^{159}$ an effect which correlated with improved behavioural performance in the Morris water maze - a sensitive procedure to test spatial orientation and learning in rodents. ${ }^{159}$

The neuroregenerative effects of $C B L$ are supported by its ability to promote neurogenesis. The effects of $\mathrm{CBL}$ on neurogenesis were studied in mThy1-hAPP751 tg mice injected once-daily with bromodeoxyuridine (BrdU, a marker for the dividing cells) followed by daily intraperitoneal injections of CBL. ${ }^{160}$ Compared with wild-type controls, saline-treated tg mice showed decreased numbers of neural progenitor cells (BrdU+ and doublecortin $\left[D C X_{+}\right]$) in the subgranular zone of the dentate gyrus. However, mThy1-hAPP751 tg mice treated with $\mathrm{CBL}$ demonstrated a significant increase in the number and migration of these newborn nervous cells, and a decrease in terminal transferase Tdt-mediated dUTP-biotin end labelling (TUNEL) apoptotic activity. CBL had no effect on cell 
proliferation or the ratio of neural progenitor cells converting to neurons and astroglia in the neurogenic area of the hippocampus. ${ }^{160}$ These findings are in line with previous studies in cultured neural progenitor cells and in normal adult rats investigating the effects of $\mathrm{CBL}$ on dentate gyrus neurogenesis. ${ }^{173}$

The protective and reparative effects of CBL have been translated into clinical trials demonstrating that $\mathrm{CBL}$ is a well-tolerated treatment for neurological disorders like ischaemic stroke, dementia and traumatic brain injury. ${ }^{173-176}$ Clinical trials with $\mathrm{CBL}$ have shown that it improves cognition in patients with mild to moderate $A D^{177-179}$ and the activities of daily living and psychiatric deficits in patients with moderate to moderately severe AD. ${ }^{164}$ Several randomised double-blind studies in patients with $A D$ have shown that $C B L$ is consistently superior to placebo at reducing cognitive alterations. ${ }^{180,181}$
Moreover, the behavioural and other functional benefits, as assessed by neuropsychiatric tests and activities of daily living, respectively, were noted to persist for several months after stopping $\mathrm{CBL}$ treatment in patients with $\mathrm{AD}$ or vascular dementia. ${ }^{180,181}$ A similar persistence of beneficial effect on spatial learning and memory following treatment interruption has been reported in the mThy1-hAPP751 tg mice. ${ }^{162}$

Collectively, the results from animal and human studies show that $\mathrm{CBL}$ has the potential to effect $\mathrm{AD}$ at many points along the pathological cascade and as such potentially provides a much broader protection than therapies aimed at a single pathological mechanism alone. It is likely that this broad-spectrum approach, coupled with a biomarker-driven earlier detection of $A D$ may represent the future of AD therapy.
1. Alzheimer's Association, 2010 Alzheimer's disease facts and figures, Alzheimers Dement, 2010;6:158-94.

2. DeKosky ST, Scheff SW, Synapse loss in frontal cortex biopsies in Alzheimer's disease: correlation with cognitive severity, Ann Neurol, 1990;27:457-64.

3. DeKosky ST, Scheff SW, Styren SD, Structural correlates of cognition in dementia: quantification and assessment of synapse change, Neurodegeneration, 1996;5:417-21.

4. Terry RD, Masliah E, Salmon DP, et al., Physical basis of cognitive alterations in Alzheimer disease: synapse loss is the major correlate of cognitive impairment, Ann Neurol, 1991;30:572-80

5. Klucken J, McLean PJ, Gomez-Tortosa E, et al , Neuritic alterations and neural system dysfunction in Alzheimer's disease and dementia with Lewy bodies, Neurochem Res, 2003;28:1683-91

6. Spires-Jones TL, Stoothoff WH, de Calignon A, et al., Tau pathophysiology in neurodegeneration: a tangled issue, Trends Neurosci, 2009;32:150-9.

7. Selkoe DJ, Amyloid beta protein precursor and the pathogenesis of Alzheimer's disease, Cell, 1989;58:611-2.

8. Selkoe D, Amyloid b-protein deposition as a seminal pathogenic event in AD: an hypothesis, Neurobiol Aging, 1990;11:299.

9. Selkoe $D$, Physiological production of the b-amyloid protein and the mechanisms of Alzheimer's disease, Trends Neurosci. 1993;16:403-9

10. Grundke-Iqbal I, Iqbal K, Tung YC, et al., Abnorma phosphorylation of the microtubule-associated protein tau (tau) in Alzheimer cytoskeletal pathology, Proc Natl Acad Sci U S A, 1986;83:4913-7.

11. Kosik KS, Joachim CL, Selkoe DJ, Microtubule-associated protein tau (tau) is a major antigenic component of paired helical filaments in Alzheimer disease, Proc Natl Acad Sci U S A, 1986:83:4044-8.

12. Wood JG, Mirra SS, Pollock NJ, Binder LI, Neurofibrillary tangles of Alzheimer disease share antigenic determinants with the axonal microtubule-associated protein tau (tau), Proc Natl Acad Sci U S A, 1986;83:4040-3.

13. Sisodia SS, Price DL, Role of the beta-amyloid protein in Alzheimer's disease, FASEB J, 1995:9:366-70.

14. Mucke L, Masliah E, Yu GQ, et al., High-level neuronal expression of abeta 1-42 in wild-type human amyloid protein precursor transgenic mice: synaptotoxicity without plaque formation, I Neurosci, 2000:20:4050-8.

15. Pérez M, Morán MA, Ferrer I, et al., Phosphorylated tau in neuritic plaques of APP(sw)/Tau (vIw) transgenic mice and Alzheimer disease, Acta Neuropathol, 2008;116:409-18.

16. Pham E, Crews L, Ubhi K, et al., Progressive accumulation of amyloid-beta oligomers in Alzheimer's disease and in amyloid precursor protein transgenic mice is accompanied by selective alterations in synaptic scaffold proteins, FEBS J, 2010;277:3051-67.

17. Ribé EM, Pérez M, Puig $B$, et al., Accelerated amyloid deposition, neurofibrillary degeneration and neuronal loss in double mutant APP/tau transgenic mice, Neurobiol Dis, 2005;20:814-22

18. Glabe CC, Amyloid accumulation and pathogensis of Alzheimer's disease: significance of monomeric, oligomeric and fibrillar Abeta, Subcell Biochem, 2005;38:167-77.

19. Klein WL, Abeta toxicity in Alzheimer's disease: globular oligomers (ADDLs) as new vaccine and drug targets, Neurochem Int, 2002;41:345-52.

20. Klein WL, Krafft GA, Finch CE, Targeting small Abeta oligomers: the solution to an Alzheimer's disease conundrum?, Trends Neurosci, 2001:24:219-24.

21. Walsh DM, Selkoe DJ, Oligomers on the brain: the emerging role of soluble protein aggregates in neurodegeneration, Protein Pept Lett, 2004;11:213-28

22. Sardi F, Fassina L, Venturini L, et al., Alzheimer's disease, autoimmunity and inflammation. The good, the bad and the ugly, Autoimmun Rev, 2011;11:149-53.
23. Sastre M, Richardson JC, Gentleman SM, Brooks DJ Inflammatory risk factors and pathologies associated with Alzheimer's disease, Curr Alzheimer Res, 2011;8:132-41.

24. Haass C, Kaether C, Thinakaran G, Sisodia S, Trafficking and proteolytic processing of APP, Cold Spring Harb Perspect Med, 2012;2:a006270.

25. Price DL, Sisodia SS, Gandy SE, Amyloid beta amyloidosis in Alzheimer's disease, Curr Opin Neurol, 1995;8:268-74.

26. Selkoe DJ, Amyloid beta-protein precursor: new clues to the genesis of Alzheimer's disease, Curr Opin Neurobiol 1994;4:708-16.

27. Gorman PM, Chakrabartty A, Alzheimer beta-amyloid peptides: structures of amyloid fibrils and alternate aggregation products, Biopolymers, 2001:60:381-94.

28. Arbel M, Solomon B, A novel immunotherapy for Alzheimer's disease: antibodies against the beta-secretase cleavage site of APP, Curr Alzheimer Res, 2007;4:437-45.

29. Arbel M, Yacoby I, Solomon B, Inhibition of amyloid precursor protein processing by beta-secretase through site-directed antibodies, Proc Natl Acad Sci U S A 2005;102:7718-23.

30. Dovey HF, John V, Anderson JP, et al., Functional gammasecretase inhibitors reduce beta-amyloid peptide levels in brain, I Neurochem, 2001:76:173-81.

31. Martone RL, Zhou H, Atchison $\mathrm{K}$, et al., Begacestat (GSI-953): a novel, selective thiophene sulfonamide inhibitor of amyloid precursor protein gamma-secretase for the treatment of Alzheimer's disease, J Pharmacol Exp Ther, 2009;331:598-608.

32. Brodney MA, Auperin DD, Becker SL, et al., Diamide aminoimidazoles: a novel series of gamma-secretase inhibitors for the treatment of Alzheimer's disease, Bioorg Med Chem Lett, 2011;21:2631-6.

33. Tomita T, Iwatsubo T, Gamma-secretase as a therapeutic target for treatment of Alzheimer's disease, Curr Pharm Des, 2006;12:661-70.

34. Klein WL, Krafft GA, Finch CE, Targeting small Abeta oligomers: the solution to an Alzheimer's disease conundrum?, Trends Neurosci, 2001;24:219-24.

35. Wisniewski T, Sadowski M, Preventing beta-amyloid fibrillization and deposition: beta-sheet breakers and pathological chaperone inhibitors, BMC Neurosci. 2008;9(Suppl. 2):S5.

36. Eckman $\mathrm{EA}$, Eckman $\mathrm{CB}$, Abeta-degrading enzymes: modulators of Alzheimer's disease pathogenesis and targets for therapeutic intervention, Biochem Soc Trans, 2005:33:1101-5.

37. Jaeger PA, Pickford $F$, Sun $\mathrm{CH}$, et al., Regulation of amyloid precursor protein processing by the Beclin 1 complex. PLos One, 2010;5:e11102

38. Ghosh AK, Brindisi M, Tang J, Developing $\beta$-secretase inhibitors for treatment of Alzheimer's disease, J Neurochem 2012;120(Suppl. 1):71-83

39. Sankaranarayanan S, Holahan MA, Colussi D, et al., First demonstration of cerebrospinal fluid and plasma $\mathrm{A}$ beta lowering with oral administration of a beta-site amyloid precursor protein-cleaving enzyme 1 inhibitor in nonhuman primates, J Pharmacol Exp Ther, 2009:328:131-40.

40. Wolfe MS, gamma-Secretase in biology and medicine, Semin Cell Dev Biol, 2009;20:219-24.

41. Wolfe MS, Inhibition and modulation of gamma-secretase for Alzheimer's disease, Neurotherapeutics, 2008:5:391-8.

42. Imbimbo BP, Giardina GA, gamma-secretase inhibitors and modulators for the treatment of Alzheimer's disease: disappointments and hopes, Curr Top Med Chem, 2011:11:1555-70

43. Hook G, Hook V. Kindy M, The cysteine protease inhibitor E64d, reduces brain amyloid- $\beta$ and improves memory deficits in Alzheimer's disease animal models by inhibiting cathepsin $B$, but not BACE1, $\beta$-secretase activity, J Alzheimers Dis, 2011;26:387-408.

44. Scherzer-Attali R, Shaltiel-Karyo R, Adalist YH, et al., Generic inhibition of amyloidogenic proteins by two naphthoquinon tryptophan hybrid molecules, Proteins, 2012;80:1962-73.
45. Levy-Sakin M, Shreberk M, Daniel Y, Gazit E, Targeting insulin amyloid assembly by small aromatic molecules: toward rational design of aggregation inhibitors, Islets, 2009:1:210-5.

46. Wang J, Santa-Maria I, Ho L, et al., Grape derived polyphenols attenuate tau neuropathology in a mouse model of Alzheimer's disease, J Alzheimers Dis, 2010;22:653-61

47. Yamin G, Ono K, Inayathullah M, Teplow DB, Amyloid betaprotein assembly as a therapeutic target of Alzheimer's disease, Curr Pharm Des, 2008:14:3231-46.

48. Spencer B, Marr RA, Rockenstein E, et al., Long-term neprilysin gene transfer is associated with reduced levels of intracellular Abeta and behavioral improvement in APP transgenic mice, BMC Neurosci, 2008:9:109.

49. Rose JB, Crews L, Rockenstein E, et al., Neuropeptide $Y$ fragments derived from neprilysin processing are neuroprotective in a transgenic model of Alzheimer's disease, J Neurosci, 2009;29:1115-25.

50. Muchowski PJ, Wacker JL, Modulation of neurodegeneration by molecular chaperones, Nat Rev Neurosci, 2005;6:11-22.

1. Klettner $\mathbf{A}$, The induction of heat shock proteins as a potential strategy to treat neurodegenerative disorders, Drug News Perspect, 2004;17:299-306.

52. Gamerdinger M, Carra S, Behl C, Emerging roles of molecular chaperones and co-chaperones in selective autophagy: focus on BAG proteins, J Mol Med (Berl), 2011;89:1175-82.

53. Koga H, Cuervo AM, Chaperone-mediated autophagy dysfunction in the pathogenesis of neurodegeneration, Neurobiol Dis, 2011:43:29-37.

54. Shacka JJ, Roth KA, Zhang J, The autophagy-lysosomal degradation pathway: role in neurodegenerative disease and therapy, Front Biosci, 2008;13:718-36.

55. Benarroch $\mathrm{EE}$, Heat shock proteins: multiple neuroprotective functions and implications for neurologic disease, Neurology, 2011:76:660-7.

56. Akerfelt M, Morimoto RI, Sistonen L. Heat shock factors: integrators of cell stress, development and lifespan, Nat Rev Mol Cell Biol, 2010;11:545-55.

57. Li Z, Srivastava P, Heat-shock proteins, Curr Protoc Immunol, 2004;Appendix 1:Appendix 1

58. Evans CG, Wisén S, Gestwicki JE, Heat shock proteins 70 and 90 inhibit early stages of amyloid beta-(1-42) aggregation in vitro, I Biol Chem, 2006;281:33182-91.

59. Hoshino T, Murao N, Namba T, et al., Suppression of Alzheimer's disease-related phenotypes by expression of heat shock protein 70 in mice, J Neurosci, 2011:31:5225-34.

60. Miyata Y, Koren J, Kiray J, et al., Molecular chaperones and regulation of tau quality control: strategies for drug discovery in tauopathies, Future Med Chem, 2011;3:1523-37

61. Jinwal UK, Miyata Y, Koren J, 3rd, et al., Chemical manipulation of hsp70 ATPase activity regulates tau stability J Neurosci, 2009;29:12079-88.

62. Du Y, Dodel R, Hampel H, et al., Reduced levels of amyloid beta-peptide antibody in Alzheimer disease, Neurology, 2001;57:801-5.

63. Rosenmann H, Meiner Z, Geylis V et al., Detection of circulating antibodies against tau protein in its unphosphorylated and in its neurofibrillary tangles-related phosphorylated state in Alzheimer's disease and healthy subjects, Neurosci Lett, 2006;410:90-3.

64. Lemere CA, Masliah E, Can Alzheimer disease be prevented by amyloid-beta immunotherapy? Nat Rev Neurol, 2010;6:108-19.

65. Bacskai BJ, Kajdasz ST, McLellan ME, et al., Non-Fc-mediated mechanisms are involved in clearance of amyloid-beta in vivo by immunotherapy, I Neurosci, 2002;22:7873-8.

66. Bard F, Barbour R, Cannon C, et al., Epitope and isotype specificities of antibodies to beta -amyloid peptide for protection against Alzheimer's disease-like neuropathology, Proc Natl Acad Sci U S A, 2003;100:2023-8.

67. Kokjohn TA, Roher $A E$, Antibody responses, amyloid-beta peptide remnants and clinical effects of AN-1792 immunization in patients with $A D$ in an interrupted trial 
CNS Neurol Disord Drug Targets, 2009;8:88-97

68. Winblad B, Minthon L, Floesser A, et al., Results of the first-in-man study with the active $A b$ immunotherapy CAD-106 in Alzheimer patients, Alzheimers Dementia, 2009:5:P113-4 0112-105-105

69. Bard F, Cannon C, Barbour R, et al., Peripherally administered antibodies against amyloid beta-peptide enter the central nervous system and reduce pathology in a mouse model of Alzheimer disease, Nat Med, 2000;6:916-9.

70. Brendza RP, Bacskai BJ, Cirrito JR, et al., Anti-Abeta antibody treatment promotes the rapid recovery of amyloidassociated neuritic dystrophy in PDAPP transgenic mice, I Clin Invest, 2005:115:428-33

71. Arendash GW, Gordon MN, Diamond DM, et al., Behavioral assessment of Alzheimer's transgenic mice following longterm Abeta vaccination: task specificity and correlations between Abeta deposition and spatial memory, DNA Cell Biol 2001;20:737-44

72. Black RS, Sperling RA, Safirstein B, et al., A single ascending dose study of bapineuzumab in patients with Alzheimer disease, Alzheimer Dis Assoc Disord, 2010;24:198-203

73. Kerchner GA, Boxer AL, Bapineuzumab, Expert Opin Biol Ther, 2010;10:1121-30

74. Laskowitz DT, Kolls BJ, A phase 2 multiple ascending dose trial of bapineuzumab in mild to moderate Alzheimer disease, Neurology, 2010;74:2026; author reply 2026-7.

75. Rinne JO, Brooks DJ, Rossor MN, et al., 11C-PiB PET assessment of change in fibrillar amyloid-beta load in patients with Alzheimer's disease treated with bapineuzumab: a phase 2, double-blind, placebo-controlled ascending-dose study, Lancet Neurol, 2010;9:363-72.

76. Siemers ER, Friedrich S, Dean RA, et al., Safety and changes in plasma and cerebrospinal fluid amyloid beta after a sing administration of an amyloid beta monoclonal antibody in subjects with Alzheimer disease, Clin Neuropharmacol, 2010;33:67-73.

77. Andorfer $\mathrm{C}$, Kress $\mathrm{Y}$, Espinoza $\mathrm{M}$, et al , Hyperphosphorylation and aggregation of tau in mice expressing normal human tau isoforms, J Neurochem 2003:86:582-90

78. Goedert M, Klug A, Crowther RA, Tau protein, the paired helical filament and Alzheimer's disease, I Alzheimers Dis, 2006;9:195-207.

79. Iqbal K, Alonso Adel C, Chen S, et al., Tau pathology in Alzheimer disease and other tauopathies, Biochim Biophys Acta, 2005;1739:198-210.

80. Goedert M, Tau gene mutations and their effects, Mov Disord 2005:20(Suppl. 12):S45-52.

81. Hanger DP, Anderton BH, Noble W, Tau phosphorylation: the therapeutic challenge for neurodegenerative disease, Trends Mol Med, 2009:15:112-9.

82. Johnson GV, Stoothoff WH, Tau phosphorylation in neurona cell function and dysfunction, I Cell Sci, 2004;117:5721-9.

83. Mandelkow E, von Bergen $\mathrm{M}$, Biernat J, Mandelkow EM, Structural principles of tau and the paired helical filaments of Alzheimer's disease, Brain Pathol, 2007;17:83-90

84. Mandelkow EM, Schweers O, Drewes G, et al., Structure, microtubule interactions, and phosphorylation of tau protein, Ann N Y Acad Sci, 1996:777:96-106.

85. Asuni AA, Boutajangout A, Quartermain D, Sigurdsson EM, Immunotherapy targeting pathological tau conformers in a tangle mouse model reduces brain pathology with associate functional improvements, J Neurosci, 2007;27:9115-29.

86. Boimel M, Grigoriadis N, Lourbopoulos A, et al., Efficacy and safety of immunization with phosphorylated tau against neurofibrillary tangles in mice, Exp Neurol, 2010;224:472-85.

87. Sigurdsson $E M$, Quartermain $D$, Boutajangout $A$, Tau immunotherapy prevents cognitive decline and clears pathological tau in a tangle mouse model, Alzheimer's \& Dementia, 2008:4(4):T191-2.

88. Masliah E, Rockenstein E, Adame A, et al., Effects of alphasynuclein immunization in a mouse model of Parkinson's disease, Neuron, 2005;46:857-68

89. Masliah E, Rockenstein E, Mante M, et al., Passive immunization reduces behavioral and neuropathological deficits in an alpha-synuclein transgenic model of Lewy body disease, PLoS One, 2011;6:e19338

90. Lee SJ, Desplats P, Sigurdson C, et al., Cell-to-cell transmission of non-prion protein aggregates, Nat Rev Neurol, 2010;6:702-6.

91. Liu L, Drouet V, Wu JW, et al., Trans-synaptic spread of tau pathology in vivo, PLos One, 2012;7:e31302

92. de Calignon $A$, Polydoro $M$, Suárez-Calvet $M$, et al., Propagation of tau pathology in a model of early Alzheimer's disease, Neuron, 2012;73:685-97

93. Sultana R, Butterfield DA, Role of oxidative stress in the progression of Alzheimer's disease, I Alzheimers Dis, 2010;19:341-53

94. Bonda DJ, Wang X, Perry G, et al., Oxidative stress in Alzheimer disease: a possibility for prevention Neuropharmacology, 2010:59:290-4.

95. Viña J, Lloret A, Giraldo E, et al., Antioxidant pathways in Alzheimer's disease: possibilities of intervention, Curr Pharm Des, 2011;17:3861-4

96. Hu NW, Ondrejcak T, Rowan MJ, Glutamate receptors in preclinical research on Alzheimer's disease: update on recent advances, Pharmacol Biochem Behav, 2012;100:855-62

97. Cerpa W, Farias GG, Godoy JA, et al., Wnt-5a occludes Abeta oligomer-induced depression of glutamatergic transmission in hippocampal neurons, Mol Neurodegener, 2010;5:3.
98. Hsieh H, Boehm J, Sato C, et al., AMPAR removal underlies Abeta-induced synaptic depression and dendritic spine loss, Neuron, 2006;52:831-43.

99. Miñano-Molina AJ España J, Martín E, et al., Soluble oligomers of amyloid-beta peptide disrupt membrane trafficking of alpha-amino-3-hydroxy-5-methylisoxazole-4propionic acid receptor contributing to early synapse dysfunction, J Biol Chem, 2011;286:27311-21.

100. Li S, Hong S, Shepardson NE, et al., Soluble oligomers of amyloid Beta protein facilitate hippocampal long-term depression by disrupting neuronal glutamate uptake, Neuron 2009;62:788-801

101. Alberdi E, Sánchez-Gómez MV, Cavaliere F, et al., Amyloid beta oligomers induce $\mathrm{Ca} 2+$ dysregulation and neuronal death through activation of ionotropic glutamate receptors, Cell Calcium, 2010:47:264-72

102. Ribeiro FM, Paquet M, Cregan SP, Ferguson SS, Group ! metabotropic glutamate receptor signalling and its implication in neurological disease, CNS Neurol Disord Drug Targets, 2010;9:574-95

103. Price DL, Rockenstein E, Ubhi K, et al., Alterations in mGluR5 expression and signaling in Lewy body disease and in transgenic models of alpha-synucleinopathy-implications for excitotoxicity, PLoS One, 2010;5:e14020.

104. Malter JS, Ray BC, Westmark PR, Westmark CJ, Fragile X syndrome and Alzheimer's disease: Another story about APP and beta-amyloid, Curr Alzheimer Res, 2010;7:200-6.

105. Logan $C Y$, Nusse $R$, The Wnt signaling pathway in development and disease, Annu Rev Cell Dev Biol, 2004;20:781-810.

106. Speese SD, Budnik V, Wnts: up-and-coming at the synapse Trends Neurosci, 2007;30:268-75.

107. da Cruz e Silva OA, Henriques AG, Domingues SC, da Cruz e Silva $\mathrm{EF}$, Wnt signalling is a relevant pathway contributing to amyloid beta- peptide-mediated neuropathology in Alzheimer's disease, CNS Neurol Disord Drug Targets, 2010;9:720-6.

108. Inestrosa N, De Ferrari GV, Garrido JL, et al., Wht signaling involvement in beta-amyloid-dependent neurodegeneration Neurochem Int, 2002:41:341-4.

109. Toledo EM, Inestrosa NC, Activation of Wht signaling by lithium and rosiglitazone reduced spatial memory mpairment and neurodegeneration in brains of an APPSwe/PSEN1DeltaE9 mouse model of Alzheimer's disease, Mol Psychiatry, 2010;15:272-85, 228.

110. Rockenstein E, Torrance M, Adame A, et al., Neuroprotective effects of regulators of the glycogen synthase kinase-3beta signaling pathway in a transgenic model of Alzheimer's disease are associated with reduced amyloid precursor protein phosphorylation, J Neurosci, 2007:27:1981-91.

111. Tajes M, Gutierrez-Cuesta J, Folch J, et al., Lithium treatment decreases activities of tau kinases in a murine model of senescence, J Neuropathol Exp Neurol, 2008;67:612-23.

112. Huang $Y$, Mucke L, Alzheimer mechanisms and therapeutic strategies, Cell, 2012;148:1204-22.

113. Altman J, Das GD, Autoradiographic and histologica evidence of postnatal hippocampal neurogenesis in rats, I comp Neurol, 1965;124:319-35.

114. Mu Y, Gage FH, Adult hippocampal neurogenesis and its role in Alzheimer's disease, Mol Neurodegener, 2011;6:85.

115. Abdipranoto A, Wu S, Stayte S, Vissel B, The role of neurogenesis in neurodegenerative diseases and its implications for therapeutic development, CNS Neurol Disord Drug Targets, 2008;7:187-210

116. Yang CP, Gilley JA, Zhang G, Kernie SG, ApoE is required for maintenance of the dentate gyrus neural progenitor pool, Development, 2011:138:4351-62

117. Gadadhar A, Marr R, Lazarov O, Presenilin-1 regulates neural progenitor cell differentiation in the adult brain, I Neurosci, 2011;31:2615-23

118. Ghosal K, Stathopoulos A, Pimplikar SW, APP intracellular domain impairs adult neurogenesis in transgenic mice by inducing neuroinflammation, PLoS One, 2010;5:e11866

119. Wen PH, Hof PR, Chen X, et al., The presenilin-1 familial Alzheimer disease mutant P117L impairs neurogenesis in the hippocampus of adult mice, Exp Neurol, 2004;188:224-37.

120. Wang R, Dineley KT, Sweatt JD, Zheng $\mathrm{H}$, Presenilin 1 familial Alzheimer's disease mutation leads to defective associative learning and impaired adult neurogenesis, Neuroscience, 2004:126:305-12

121. Haughey NJ, Nath A, Chan SL, et al., Disruption of neurogenesis by amyloid beta-peptide, and perturbed neural progenitor cell homeostasis, in models of Alzheimer's disease, J Neurochem, 2002:83:1509-24

122. Masliah E, Miller A, Terry RD, The synaptic organization of the neocortex in Alzheimer's disease, Med Hypotheses, 1993;41:334-40.

123. Masliah E, Mallory M, Alford M, et al., Altered expression of synaptic proteins occurs early during progression of Alzheimer's disease, Neurology, 2001:56:127-9.

124. Masliah E, Licastro F, Neuronal and synaptic loss, reactive gliosis, microglial response, and induction of the complement cascade in Alzheimer's disease. In: Clark $C_{1}$ Trojanowski J (eds), Neurodegenerative Dementias, New York, NY, US: MCGraw-Hill, 2000;131-46.

125. Masliah E, Abraham C, Johnson W, et al., Synaptic alterations in the cortex of APP transgenic mice, I Neuropathol Exp Neurol, 1993;52:307.

126. Shankar GM, Li S, Mehta TH, et al., Amyloid-beta protein dimers isolated directly from Alzheimer's brains impair synaptic plasticity and memory, Nat Med, 2008;14:837-42.

127. Selkoe DJ, Alzheimer's disease is a synaptic failure, Science, 2002;298:789-91

28. Haass C, Selkoe DJ, Soluble protein oligomers in neurodegeneration: lessons from the Alzheimer's amyloid beta-peptide, Nat Rev Mol Cell Biol, 2007;8:101-12.

129. Crews L, Masliah E, Molecular mechanisms of neurodegeneration in Alzheimer's disease, Hum Mol Genet, 2010;19:R12-20

130. Cullen WK, Suh YH, Anwyl R, Rowan MJ, Block of LTP in rat hippocampus in vivo by beta-amyloid precursor protein fragments, Neuroreport, 1997:8:3213-7.

131. Lambert MP, Barlow AK, Chromy BA, et al., Diffusible, nonfibrillar ligands derived from Abeta1-42 are potent central nervous system neurotoxins, Proc Natl Acad Sci U S A 1998:95:6448-53.

132. Krafft GA, Klein WL, ADDLS and the signaling web that leads to Alzheimer's disease, Neuropharmacology, 2010;59:230-42

133. Walsh DM, Klyubin I, Fadeeva JV, et al., Naturally secreted oligomers of amyloid beta protein potently inhibit hippocampa long-term potentiation in vivo, Nature, 2002;416:535-9.

134. Wang HW, Pasternak JF, Kuo H, et al., Soluble oligomers of beta amyloid (1-42) inhibit long-term potentiation but not long-term depression in rat dentate gyrus, Brain Res, 2002;924:133-40

135. Shankar GM, Bloodgood BL, Townsend M, et al., Natural oligomers of the Alzheimer amyloid-beta protein induce reversible synapse loss by modulating an NMDA-type glutamate receptor-dependent signaling pathway, J Neurosci, 2007;27:2866-75.

136. Wei W, Nguyen LN, Kessels HW, et al., Amyloid beta from axons and dendrites reduces local spine number and plasticity, Nat Neurosci, 2010;13:190-6.

137. Szego EM, Csorba A, Janáky T, et al., Effects of estrogen on beta-amyloid-induced cholinergic cell death in the nucleus basalis magnocellularis, Neuroendocrinology, 2011;93:90-105

138. Nunes-Tavares N, Santos LE, Stutz B, et al., Inhibition of choline acetyltransferase as a mechanism for cholinergic dysfunction induced by amyloid-beta peptide oligomers, I Bio Chem, 2012;287:19377-85.

139. Pascual A, Hidalgo-Figueroa M, Gómez-Díaz R, López-Barneo J, GDNF and protection of adult central catecholaminergic neurons, J Mol Endocrinol, 2011;46:R83-92.

140. Bath KG, Lee FS, Neurotrophic factor control of adult SVZ neurogenesis, Dev Neurobiol, 2010;70:339-49.

141. Mattson MP, Glutamate and neurotrophic factors in neuronal plasticity and disease, Ann N Y Acad Sci, 2008;1144:97-112.

142. Elliott $E$, Ginzburg I, The role of neurotrophins and insulin on tau pathology in Alzheimer's disease, Rev Neurosci, 2006;17:635-42

143. Cole GM, Frautschy SA, The role of insulin and neurotrophic factor signaling in brain aging and Alzheimer's Disease, Exp Gerontol, 2007;42:10-21

144. Counts SE, Mufson EJ, The role of nerve growth factor receptors in cholinergic basal forebrain degeneration in prodromal Alzheimer disease, I Neuropathol Exp Neurol, 2005;64:263-72.

145. Saragovi HU, Hamel E, Di Polo A, A neurotrophic rationale for the therapy of neurodegenerative disorders, Curr Alzheimer Res, 2009;6:419-23

146. Tuszynski MH, Thal L, Pay M, et al., A phase 1 clinical trial of nerve growth factor gene therapy for Alzheimer disease Nat Med, 2005;11:551-5.

147. Rockenstein E, Mallory M, Mante M, et al., Early formation of mature amyloid-beta protein deposits in a mutant APP transgenic model depends on levels of Abeta(1-42) I Neurosci Res, 2001;66:573-82

148. Nagahara AH, Merrill DA, Coppola G, et al., Neuroprotective effects of brain-derived neurotrophic factor in rodent and primate models of Alzheimer's disease, Nat Med, 2009:15:331-7.

149. Politis $\mathrm{M}$, Lindvall $\mathrm{O}$, Clinical application of stem cell therapy in Parkinson's disease, BMC Med, 2012;10:1

150. Blurton-Jones M, Kitazawa M, Martinez-Coria H, et al., Neural stem cells improve cognition via BDNF in a transgenic model of Alzheimer disease, Proc Natl Acad Sci U S A 2009:106:13594-9.

151. Xuan AG, Long DH GU HG, et al , BDNF improves the effects of neural stem cells on the rat model of Alzheimer's disease with unilateral lesion of fimbria-fornix, Neurosci lett, 2008;440:331-5

152. Angot $\mathrm{E}$, Steiner JA, Lema Tomé $\mathrm{CM}$, et al., Alpha-synuclein cell-to-cell transfer and seeding in grafted dopaminergic neurons in vivo, PLoS One, 2012:7:e39465.

153. Kordower JH, Dodiya HB, Kordower AM, et al., Transfer of host-derived alpha synuclein to grafted dopaminergic neurons in rat, Neurobiol Dis, 2011:43:552-7.

154. Schubert D, Maher P. An alternative approach to drug discovery for Alzheimer's disease dementia, Future Med Chem 2012;4:1681-8. 
157. Kohl Z, Winner B, Ubhi K, et al., Fluoxetine rescues impaired hippocampal neurogenesis in a transgenic A53T synuclein mouse model, Eur I Neurosci, 2012:35:10-9.

158. Ubhi K, Inglis C, Mante M, et al., Fluoxetine ameliorates behavioral and neuropathological deficits in a transgenic model mouse of alpha-synucleinopathy, Exp Neurol, 2012;234:405-16.

159. Rockenstein E, Adame A, Mante M, et al., The neuroprotective effects of Cerebrolysin in a transgenic model of Alzheimer's disease are associated with improved behavioral performance, J Neural Transm, 2003;110:1313-27.

160. Rockenstein $E$, Mante M, Adame A, et al., Effects of Cerebrolysin on neurogenesis in an APP transgenic model of Alzheimer's disease, Acta Neuropathol, 2007;113:265-75

161. Rockenstein $E$, Torrance M, Mante M, et al., Cerebrolysin decreases amyloid-beta production by regulating amyloid protein precursor maturation in a transgenic model of Alzheimer's disease, J Neurosci Res, 2006;83:1252-61.

162. Rockenstein E, Ubhi K, Pham E, et al., Beneficial effects of a neurotrophic peptidergic mixture persist for a prolonged period following treatment interruption in a transgenic (n) interruption in a transgenic model of Alzheimer's

163. Alvarez XA, Cacabelos $R$, Sampedro $C$, et al., Combination treatment in Alzheimer's disease: results of a randomized, controlled trial with cerebrolysin and donepezil, Curr Alzheimer Res, 2011;8:583-91.

164. Alvarez XA, Cacabelos R, Sampedro C, et al., Efficacy and safety of Cerebrolysin in moderate to moderately severe Alzheimer's disease: results of a randomized, double-blind, controlled trial investigating three dosages of Cerebrolysin, Eur J Neurol, 2011:18:59-68.

165. Alvarez XA, Cacabelos $R$, Laredo $M$, et al, A 24-week double-blind, placebo-controlled study of three dosages of Cerebrolysin in patients with mild to moderate Alzheimer's disease, Eur I Neurol, 2006;13:43-54.

166. Chen H, Tung YC, Li B, et al., Trophic factors counteract elevated FGF-2-induced inhibition of adult neurogenesis, Neurobiol Aging, 2007;28:1148-62.

167. Akai F, Hiruma S, Sato T, et al., Neurotrophic factor-like effect of FPF1070 on septal cholinergic neurons after transections of fimbria-fornix in the rat brain, Histol Histopathol, 1992;7:213-21.

168. Francis-Turner L, Valouskova V, Nerve growth factor and nootropic drug cerebrolysin but not fibroblast growth factor can reduce spatial memory impairment elicited by fimbriafornix transection: short-term study, Neurosci Lett, 1996;202:193-6

169. Francis-Turner L, Valouskova V, Mokry J, The long-term effect of NGF, b-FGF and Cerebrolysin on the spatial memory after fimbria-fornix lesion in rats, I Neural Transm suppl, 1996;47:277.

170. Zhang C, Chopp M, Cui Y, et al., Cerebrolysin enhances neurogenesis in the ischemic brain and improves functiona outcome after stroke, J Neurosci Res, 2010;88:3275-81.

171. Ubhi K, Rockenstein E, Vazquez-Roque R, et al, Cerebrolysin modulates pronerve growth factor/nerve growth factor ratio and ameliorates the cholinergic deficit in a transgenic model of Alzheimer's disease, J Neurosci Res, 2012. [Epub ahead of print]

172. Ubhi K, Rockenstein E, Doppler E, et al., Neurofibrillary and neurodegenerative pathology in APP-transgenic mice injected with AAV2-mutant TAU: neuroprotective effects of
Cerebrolysin, Acta Neuropathol, 2009;117:699-712. 173. Masliah E, Diez-Tejedor E, The pharmacology of neurotrophic treatment with Cerebrolysin: brain protection and repair to counteract pathologies protection and repair to counteract patholog
of acute and chronic neurological disorders, of acute and chronic neurological disorders
Drugs Today (Barc), 2012;48(Suppl. A):3-24.

174. Thome J, Doppler E, Safety profile of Cerebrolysin: clinical experience from dementia and stroke trials, Drugs Today (Barc), 2012;48(Suppl. A):63-9.

175. Ziganshina LE, Abakumova T, Kuchaeva A, Cerebrolysin for acute ischaemic stroke, Cochrane Database Syst Rev, 2010:CD007026.

176. Bornstein N, Poon WS, Accelerated recovery from acute brain injuries: clinical efficacy of neurotrophic treatment in stroke and traumatic brain injuries, Drugs Today (Barc), 2012; 48 (Suppl. A):43-61

177. Alvarez XA, Cacabelos R, Laredo M, et al., A 24-week double-blind, placebo-controlled study of three dosages of Cerebrolysin in patients with mild to moderate Alzheimer's disease, Eur J Neurol, 2006;13:43-54.

178. Ruther E, Ritter R, Apecechea M, et al., Sustained improvements in patients with dementia of Alzheimer's type (DAT) 6 months after termination of Cerebrolysin therapy, I Neural Transm, 2000:107:815-29.

179. Rüther $E$, Ritter R, Apecechea M, et al., Efficacy of the peptidergic nootropic drug cerebrolysin in patients with senile dementia of the Alzheimer type (SDAT), Pharmacopsychiatry, 1994;27:32-40.

180. Plosker GL, Gauthier S, Spotlight on cerebrolysin in dementia, CNS Drugs, 2010;24:263-6.

181. Plosker GL, Gauthier S, Cerebrolysin: a review of its use in dementia, Drugs Aging, 2009:26:893-915. 